\title{
Peculiarities of promiscuous L-threonine transaldolases for enantioselective synthesis of $\beta$-hydroxy- $\alpha$-amino acids
}

\author{
Shan Wang ${ }^{1} \cdot$ Hai Deng ${ }^{1}$ \\ Received: 17 February 2021 / Revised: 31 March 2021 / Accepted: 7 April 2021 / Published online: 26 April 2021 \\ (C) The Author(s) 2021
}

\begin{abstract}
The introduction of $\beta$-hydroxy- $\alpha$-amino acids ( $\beta$ HAAs) into organic molecules has received considerable attention as these molecules have often found widespread applications in bioorganic chemistry, medicinal chemistry and biomaterial science. Despite innovation of asymmetric synthesis of $\beta$ HAAs, stereoselective synthesis to control the two chiral centres at $\mathrm{C}_{\alpha}$ and $\mathrm{C}_{\beta}$ positions is still challenging, with poor atomic economy and multi protection and deprotection steps. These syntheses are often operated under harsh conditions. Therefore, a biotransformation approach using biocatalysts is needed to selectively introduce these two chiral centres into structurally diverse molecules. Yet, there are few ways that enable one-step synthesis of $\beta$ HAAs. One is to extend the substrate scope of the existing enzyme inventory. Threonine aldolases have been explored to produce $\beta$ HAAs. However, the enzymes have poor controlled installation at $C_{\beta}$ position, often resulting in a mixture of diastereoisomers which are difficult to be separated. In this respect, L-threonine transaldolases (LTTAs) offer an excellent potential as the enzymes often provide controlled stereochemistry at $C_{\alpha}$ and $C_{\beta}$ positions. Another is to mine LTTA homologues and engineer the enzymes using directed evolution with the aim of finding engineered biocatalysts to accept broad substrates with enhanced conversion and stereoselectivity. Here, we review the development of LTTAs that incorporate various aldehyde acceptors to generate structurally diverse $\beta$ HAAs and highlight areas for future developments.
\end{abstract}

\section{Key points}

- The general mechanism of the transaldolation reaction catalysed by LTTAs

- Recent advances in LTTAs from different biosynthetic pathways

- Applications of LTTAs as biocatalysts for production of BHAAs

Keywords L-threonine transaldolases (LTTAs) $\cdot \beta$-Hydroxy- $\alpha$-amino acids ( $\beta$ HAAs) $\cdot$ Stereoselective chemoenzymatic synthesis $\cdot$ Natural product biosynthesis

\section{Introduction and scope of the review}

Nature often employs non-canonical amino acids that bear new and different functional groups to tune the properties of bioactive small molecules (Hibi et al. 2015). There are dozens of known modifications to proteogenic amino acids, including a wide variety that bears a hydroxyl group at the $\beta$-carbon. $\beta$ -

Shan Wang

shan.wang@abdn.ac.uk

Hai Deng

h.deng@abdn.ac.uk

1 Department of Chemistry, University of Aberdeen, Aberdeen, Scotland AB24 3UE, UK
Hydroxy- $\alpha$-amino acids ( $\beta$ HAAs) are an important class of compounds, the majority of which contain two chiral centres at $\mathrm{C}_{\alpha}$ and $\mathrm{C}_{\beta}$ position, resulting in four possible diastereoisomers (Ashford and Bew 2012). They are valuable constituents of medicinally important compounds and complex natural products (Hibi et al. 2015). For instance, L-threo-3,4dihydroxyphenylserine (Droxidopa) 1 (Fig. 1) is a currently used therapeutic for the treatment of Parkinson disease (Maruyama et al. 1996; Hauser et al. 2016). $\beta$ HAAs have also been used as intermediates in the biosynthesis of $\beta$-lactones such as obafluorin 2 (Fig. 1) (Schaffer et al. 2017; Scott et al. 2017). L-threo-p-nitrophenylserine and its derivative are the key components of amino alcohol antibiotics, chloramphenicol 3 (Seiple et al. 2014), its synthetic derivatives thiamphenicol $\mathbf{4 a}$ and fluorfenicol $\mathbf{4 b}$ and 4-fluorothreonine 
Fig. $1 \beta$-hydroxy- $\alpha$-amino acids ( $\beta$ HAAs) serve as building blocks for many biological active chemicals and pharmaceutical drugs

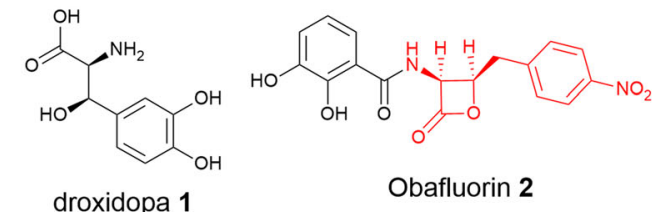<smiles>CC1C(OC2C(=O)OC(CO)C(O)C2O)C[C@@H](N)C(C)C1O</smiles><smiles>[R]CC(N[C@H](COC)C(=O)O)C(O)c1ccc(OC(C)=O)cc1</smiles>

Chloramphenicol $3 \quad \mathrm{R}=\mathrm{OH}$ thiamphenicol $4 \mathrm{a}$ $\mathrm{R}=\mathrm{F}$ florfenicol<smiles>NCC(O)C(N)CF</smiles>

$4 b$

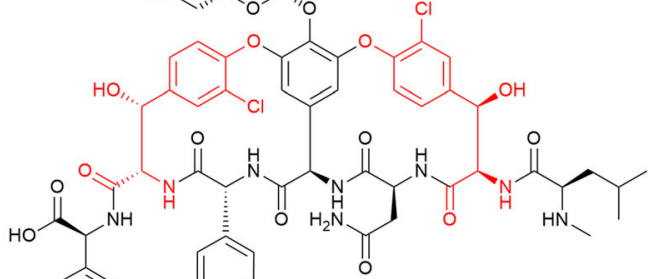<smiles>Oc1ccc(-c2ccccc2O)c(O)c1</smiles>

vancomycin 6

4-fluorothreonine 5

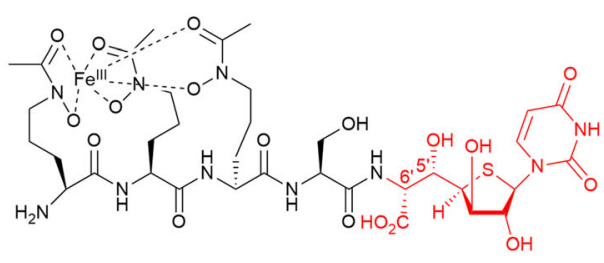

albomycin $\delta_{1} 7$

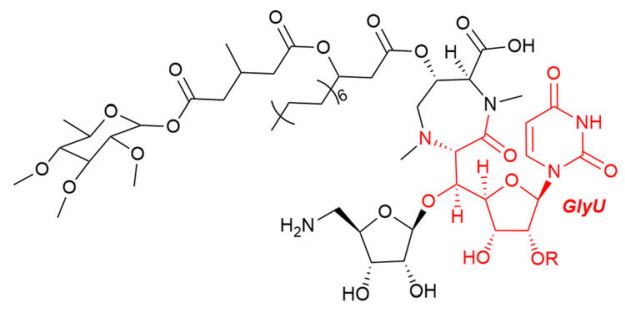

$\mathrm{R}=\mathrm{SO}_{3} \mathrm{H} \quad \mathrm{A}-90289 \mathrm{~A} \quad \mathbf{8}$

$\mathrm{R}=\mathrm{H} \quad$ Caprazamycin $\mathrm{A} 9$
5 (Fig. 1) (Lu et al. 2008); $\beta$-hydroxytyrosine and $\beta$ hydroxyphenylalanine residues are found in clinically active glycopeptide antibiotics, such as vancomycin 6 (Fig. 1) (Yim et al. 2014). Nucleotide-containing $\beta$ HAA is the crucial motif of the nucleoside antibiotic natural products 7-9 (Fig. 1) (Barnard-Britson et al. 2012; Cai et al. 2015; Ushimaru and Liu 2019). $\beta$ HAAs are also common synthetic precursors to $\beta$-lactams and aziridine carboxylic acid derivatives in synthetic chemistry and to chiral bisoxazoline ligands for metal catalysis (Masruri et al. 2012).

These diverse applications underlie a broad interest in understanding $\beta$ HAA production and utilization in nature. Accordingly, several methods have been devised for the asymmetric syntheses of $\beta$ HAAs including asymmetric aldol reaction (Sugiyama et al. 2002 and Singjunla et al. 2013), sharpless asymmetric dihydroxylations (Masruri et al. 2012), stereoselective electrosynthesis using trans-metal Schiff base complexes (Levitskiy et al. 2019) and numerous others. The main challenge is the control of the relative and absolute stereochemistry of the asymmetric carbons in the current trend of sustainable development.

Compared to non-enzymatic synthesis, an attractive alternative is enzymatic synthesis of $\beta$ HAAs via a one-step process under mild conditions as a means of potentially more atom-economic and greener. There have been considerable attentions that are focused on those promising biotransformation strategies for asymmetric synthesis of $\beta$ HAAs. Nature has evolved different enzymatic routes to produce these useful compounds. Free amino acids can undergo stereo-specific and -selective $\mathrm{C} \beta$ hydroxylation, as illustrated by the non-heme Fe-dependent hydroxylation of homotyrosine in the biosynthesis of echinocandins (Hüttel. 2021). Another common biosynthetic strategy is for an amino acid to be loaded onto a nonribosomal peptide synthetase (NRPS), whereupon a P450 enzyme catalyses $C \beta$ hydroxylation of an aminoacyl-S-enzyme intermediate en-route to a peptide natural product as observed in the biosynthesis of vancomycin $\mathbf{1}$ (Tailhades et al. 2020).

Threonine aldolases (TAs), which catalyse a reversible chemical reaction of cleavage of threonine into glycine and acetaldehyde, have been reported as such biocatalysts using various aldehydes and glycine as substrates to generate useful BHAAs (Fesko 2016). However, the poor enantioselectivity at $\mathrm{C}_{\beta}$ hampers their further application as side products are generated. In contrast, there is a remarkable set of pyridoxal5'-phosphate (PLP)-dependent enzymes, L-threonine transaldolases (LTTAs), which catalyse retroaldol cleavage of L-threonine (Thr) and a subsequent aldol-like addition into an aldehyde to form a new side chain, setting the stereochemistry of the $\mathrm{C}_{\beta}-\mathrm{OH}$ group. It is worth noting that phylogenetic analysis suggested that LTTAs are evolutionary distinct from L-threonine aldolases (LTAs) and SHMTs (Scott et al. 2017; Wu et al. 2020).

This review surveys the recent advances of LTTAs discovered in the biosynthetic pathways as potential biocatalysts, highlighting the unique biochemical transformations and their substrate promiscuity. Particular emphasis is placed on exploring the existing LTTA inventory for the production of structurally diverse $\beta$ HAAs. Furthermore, bioengineering of 
such enzymes will certainly advance our abilities to engineer a suitable biotechnologically viable catalyst for $\beta$ HAA production. Other PLP-dependent enzymatic reactions discovered from natural product biosynthesis can be found in the recent review (Du and Ryan 2019). Another family of transaldolases from the pentose phosphate pathway, catalysing the reversible transfer of a dihydroxyacetone moiety between ketose donors and aldose acceptors (D-glyceraldehyde-3-phosphate, or Derythrose-4-phosphate), was summarized in a review (Samland et al. 2011). Therefore, this group of transaldolases will be out of the scope in the current report.

Although the first LTTA, 4-fluorothreonine transaldolase (FTase), was identified in 2001 (Murphy et al. 2001), it was not until 11 years later in 2012 that a second LTTA was identified (Barnard-Britson et al. 2012). Since then, five new LTTA homologues have been discovered during the biosynthetic studies of various bioactive natural products, coincided with the advanced genome sequencing technology during the last decade. It is noteworthy that while FTases are didomain LTTAs, newly discovered LTTAs are single-domain enzymes. Automated annotation of the sequenced genomes has miscategorized many LTTA-like open reading frames (ORFs) in microbial genomes as serine hydroxymethyltransferase (SHMT)-like enzymes (Scott et al. 2017). However, these LTTA-like ORFs share low homologues (25-35\% aa identity) to SHMTs. Therefore, new LTTA homologues with improved kinetics and broad substrate specificity could be identified and characterized through conserved genomic mining of biotechnological purpose for asymmetric synthesis of $\beta$ HAAs. This review will serve as a compendium to communities of microbiologists, organic chemists, natural product chemists, biochemists, synthetic biologists, and many others interested in the subject.

\section{The general mechanism of LTTAs}

All of the LTTA enzymes utilize PLP as the cofactor. The catalytic cycle starts and ends with the same PLP cofactor form (the internal aldimine 10), which is derived from transamination and heterolytic cleavage to maintain the carbanionic intermediates (Richard et al., 2009). The internal aldimine structure consists of an imine linkage between the amino group of a lysine residue from the enzyme and the aldehyde carbon of free PLP. Then, within the interaction of L-Thr, a geminal diamine intermediate $\mathbf{1 1}$ is formed which finally leads to the PLP:external aldimine 12 allowing substrate binding and product release (Fig. 2). Additionally, the proton in the external aldimine can transfer (or is shared) between oxygen in the pyridine ring and imine nitrogen forming two tautomeric isoforms, enolimine $\mathbf{1 2}$ and ketoenamine 12a separately. This transformation shows specific maximal absorbance values at $335 \mathrm{~nm}$ for enolimine 12a and $425 \mathrm{~nm}$ for ketoenamine 12 when analysed by ultraviolet-visible (UV-Vis) spectroscopy.

The PLP:external aldimine $\mathbf{1 2}$ is the crucial intermediate for all LTTAs. Meanwhile, the efficiency of the PLP enzymatic reaction is predominately dependent on the heteroaromatic pyridine ring. The electrophilicity of the $\mathrm{C} 4$ of the external aldimine is enhanced because of the protonated pyridinium nitrogen, the resonance and hydrogen bonding of the hydroxyl group, leading to an 'electron sink'. Therefore, the protonated imine nitrogen can withdraw electrons from the substrate. The $\pi$-conjugation of the pyridine ring delocalizes and stabilizes the net-negative charge of external aldimine. Due to the electronic delocalization energy, the stereochemical rearrangement of $\sigma$ bonds is activated by a $\pi$ system, forming the Dunathan intermediate 12b (Fig. 2b). The deprotonation of hydroxyl group at $\mathrm{C} \beta$ of $\mathrm{L}-\mathrm{Thr}$ residue results in a retroaldol cleavage between the $\mathrm{C}_{\alpha}-\mathrm{C}_{\beta}$ bond, promoting the bondbreaking process of the perpendicular bond of the pyridine ring 13a (Fig. 2b). As a consequence, the heterolytic cleavage happens, and the $\mathrm{C}_{\alpha}$ hybridization changes generate the resonance-stabilized ubiquitous quinonoid intermediate $\mathbf{1 3}$ which displays specific maximal absorbance values at 495 $\mathrm{nm}$. However, the quinonoid intermediate has not always been observed by UV-Vis spectroscopy in many the PLPdependent reactions, suggesting that they may be extremely short lived or transient. A subsequent aldol-like addition into an aldehyde forms a new side chain 14, setting the stereochemistry of the $\mathrm{C} \beta-\mathrm{OH}$ group to yield new L-threo- $\alpha$ hydroxy- $\beta$-amino acids $\mathbf{1 5}$ after hydrolysis (Fig. 2a). It is worth noting that LTTAs are evolutionarily divergent from TAs as such the first half of the biochemical pathway of LTTAs processes a retroaldol reaction, significantly different from TAs.

\section{Discovery of L-Thr transaldolases from the biosynthetic pathways of natural products}

\section{The discovery of the didomain 4-fluorothreonine transaldolases (FTases)}

Fluorine has emerged as a privileged element in medicinal chemistry as well as in agrochemistry and materials science (O'Hagan and Deng 2015). Fluorine substitutions are now considered a standard strategy for modulating the properties of chemical leads, despite that environmental contamination by organofluorines is an issue of major concern due to their persistence to biodegradation (Moreira et al. 2018). While many chemical methods of selective synthesis of organofluorines have been developed, it is attractive to consider biotransformation approaches to selectively access novel organofluorine chemicals, rather than using challenging 


\section{a}<smiles></smiles>

The Schiff base between the active site lysine and PLP<smiles></smiles>

internal aldimine $\mathbf{1 0}$ ketoenamine UV maximum $415-425 \mathrm{~nm}$

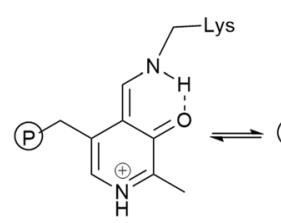

internal aldimine $10 a$ enolimine UV maximum 315-325 nm

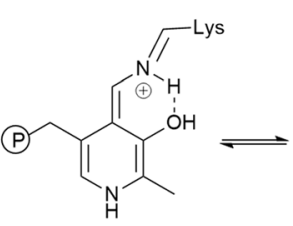

internal quinonoid $10 \mathrm{~b}$ UV maximum $515 \mathrm{~nm}$

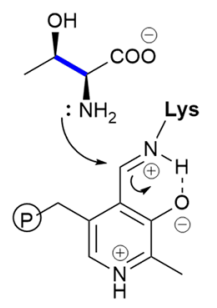

The Schiff base between the substrate and PLP

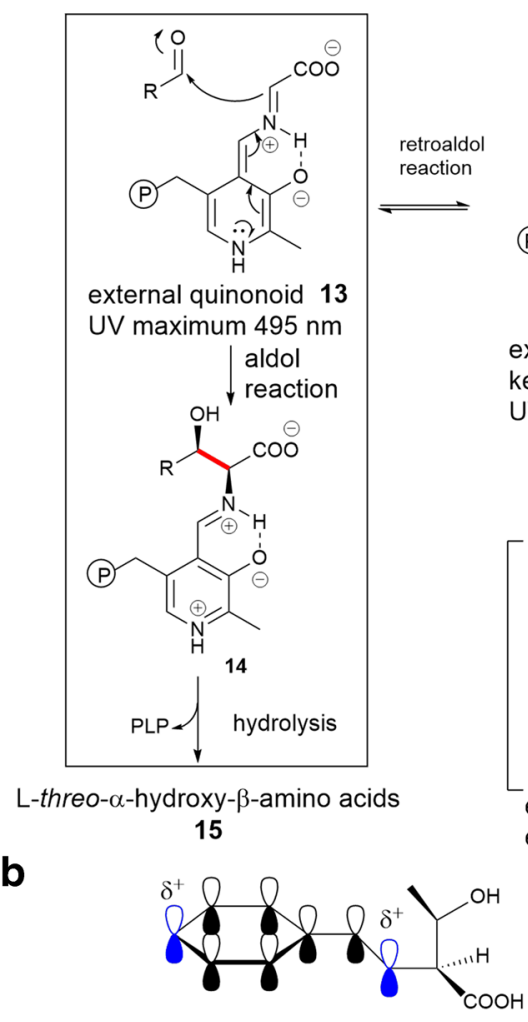

Dunathan intermediate 12b

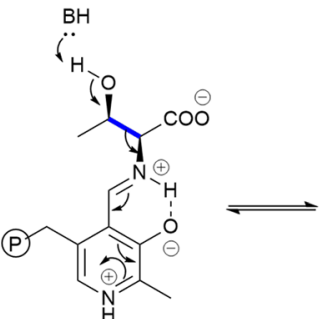

external aldimine 12 ketoenamine UV maximum $415-425 \mathrm{~nm}$<smiles>[CH]C</smiles>

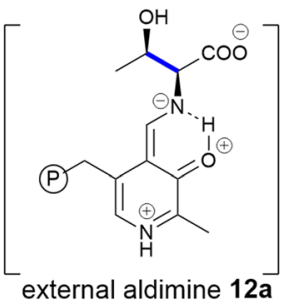
enolimine

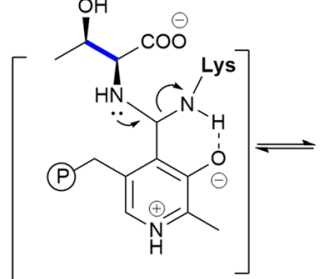

gem-diamine || 11a

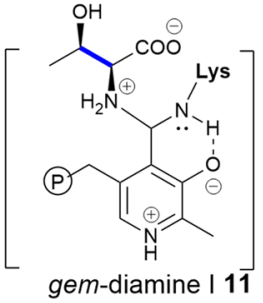

gem-diamine | 11
(P) phosphate moiety

blue bond: "old" $C \alpha-C \beta$ bond red bond: "new" $\mathrm{C} \alpha-\mathrm{C} \beta$ bond

Fig. 2 a A generic mechanism of the transaldolation reaction catalysed by LTTAs. b The schematic representation of Dunathan intermediate 12a and quinonoid intermediate 13a

chemical methods (Wu et al. 2020). Fluorinated NPs are rare, mainly due to the highest heat hydration of fluoride in water which makes fluoride a poor nucleophile. As a result, there are only a handful of fluorinated natural products discovered by organic chemists in natural product inventory. 4Fluorothreonine (4-FT) $\mathbf{5}$ is the only fluorinated amino acid natural product discovered thus far. It was found to be a cooccurrent metabolite with another fluorinated toxic, fluoroacetate (FAc) 16, in the culture broth of the soil bacterium Streptomyces cattleya in 1986 (Fig. 3a) (Sanada et al. 1986). O'Hagan and co-workers have conducted the seminal work on elucidation of the fluorometabolism in $S$. cattleya (Deng et al. 2004). They demonstrated that fluoroacetaldehyde (FAd) 17 is the precursor of 4-FT (Hamilton et al. 1997; Nieschalk et al. 1997; Moss et al.
2000), but glycine is not directly contributed to the 4-FT biosynthesis (Hamilton et al. 1998) in their early isotopic labelling studies, suggesting that the biotransformation of FAd $\mathbf{1 7}$ to 4-FT 5 is not descended from a classical aldolase reaction. In 2001, the enzyme, 4-fluorothreonine transaldolase (4FTase), responsible for the production of 4-FT, was purified from $S$. cattleya (Murphy et al. 2001). Biochemical analysis using a combination of isotopic labelling experiments and GC-MS analysis demonstrated that this wild-type enzyme actually catalyses a PLP-dependent cross-over transaldolation reaction between FAd and L-Thr to give 4-FT and acetaldehyde as shown in Fig. $3 \mathrm{a}$. The hallmark of the fluorometabolism studies is the discovery of the first native fluorination enzyme, fluorinase (FlA), which catalyses C-F bond formation between fluoride ion and $S$-adenosyl-L- 


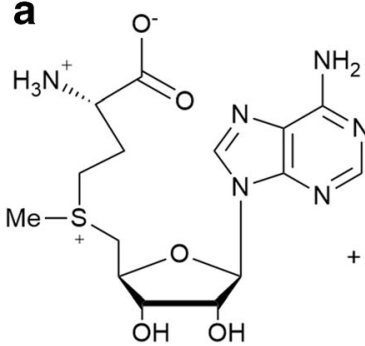

SAM 18

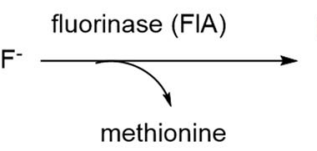

methionine 5'-FDA 19<smiles>[R]C(O)[C@H](N)C(=O)O</smiles>

20

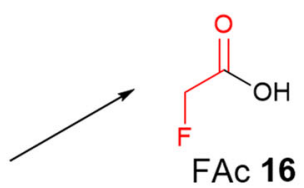

FAc 16<smiles>C[C@H](O)[C@@H](N)C(=O)O</smiles>

4-FT 4

b<smiles>[R]C=O</smiles>

C

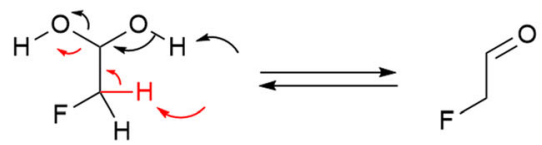

FAd hydrate 17a
FAd enol form 17b

Fig. 3 a The biosynthetic pathways of 4-fluorothreonine and fluoroacetate, highlighted with the first committed enzymatic step in the pathway of the fluorination enzyme. The fluorinase (F1A) in Streptomyces cattleya and Streptomyces sp. MA37 (MA37). b FTaseMA from MA37, the close homologue of the original FTase identified in $S$. cattleya,

\section{FAd aldehydic form 17}

displays broad substrate specificity toward various aldehyde acceptors. c The proposed mechanism of the dehydration of FAd hydrate 17a to FAd aldehydic form $\mathbf{1 7}$ catalysed by the second small domain of FTaseMA for the transaldolation reaction

converted to 4-FT involving five overexpressed enzymes, including recombinant fluorinase and FTase (Deng et al. 2008). Inactivation of flFT in $S$. cattleya resulted in the sole production of fluoroacetate (Zhao et al. 2012), further confirming the role of FTase in 4-FT biosynthesis.

The genome sequencing efforts of the second decade of the twenty-first century have revealed that another four actinomycete strains encode the $f l A$ genes, suggesting that these four new strains may have capacity to produce fluorometabolites (Deng et al. 2014; Huang et al. 2014; Wang et al. 2014). Of particular relevance here is the strain isolated from a Ghanaian soil sample, Streptomyces sp. MA37. In culture, the organism had the capacity to biosynthesise 4-FT 5 and FAc 16, as well as a range of other minor fluorometabolites (Ma et al. 2015; Wu et al. 2020). The flFT homologues encoding the last step of 4-FT biosynthesis are in close proximity to the corresponding $f l A$ homologue, in line with expectation. This is not the case for $S$. cattleya, where flFT is located on the megaplasmid pSCATT (1.8 Mbp in length) and the flA gene is on the chromosome of $S$. cattleya (Zhao et al. 2012).

More recently, the overexpression of flFT homologous gene (flFTMA) from Streptomyces sp. MA37 in different hosts was carried out for detailed biochemical analysis (Wu et al. 2020). Among three Streptomyces hosts (S. lividans TK24, 
S. lividans 66 and S. albus J-1074), the S. lividans 66 recombinant variant gave the highest production of 4-FT while the least activity was found in S. lividans TK24 recombinant strain. The recombinant protein (FTaseMA) was purified to near homogeneity as a bright yellow protein with UV absorbance maxima at 335 and $425 \mathrm{~nm}$, in which the enolimine peak at $325 \mathrm{~nm}$ is dominant. The stoichiometry between bound PLP and the protein was estimated to be $1: 1$. Incubation of the purified recombinant enzyme with L-Thr, FAd and PLP resulted in the production of 4-FT 5, demonstrating that the recombinant protein is functional ( $\mathrm{Wu}$ et al. 2020).

FTases are unusual enzymes in that they use FAd $\mathbf{1 7}$ as a substrate, which is heavily hydrated in water as FAd hydrate 17a (Fig. 3c) (Cobb et al. 2004). As a result, the enzymes appear to evolve specific ability of accelerating the transformation of FAd hydrate 17a to the aldehyde form 17 or FAd enol form $\mathbf{1 7 b}$ for the next transaldolation reaction (Fig. 3c). This is in line with the hybrid construction of functional FTases that have a small domain (A domain) homologous to aldolase/epimerase possibly involving the dehydrate reaction. Structural prediction of this A domain suggested good structural similarity with the metal-dependent class II aldolases (Wu et al. 2020). The active sites of these aldolases normally contain a catalytic tetrad of Glu-His-His-His, the latter three His residues of which coordinate a divalent metal acting as a Lewis acid type catalyst. The general mechanism of these aldolases involves the first Glu residue directing proton transfer of the aldol to generate an enediol intermediate, coordinated by the bound zinc. Examination of the predicted structure of the aldolase/epimerase domain of FTaseMA suggested a catalytic tetrad, Glu573-His551-His553-His598, with the essential residue of Asn484 that may position Glu573 residue towards the active site through hydrogen bonds. Indeed, elemental analysis of FTaseMA demonstrated that the stoichiometry of the bound zinc and the enzyme was estimated to be 1:1 (Wu et al. 2020). Alanine-scanning mutagenesis of the three His and Asn residues significantly reduced the production of 4-FT 5, suggesting that these four residues are important ( $\mathrm{Wu}$ et al. 2020). The mutated FTaseMA variant, in which Glu573 was changed to Ala, however, caused the instability of the purified protein for further biological evaluation.

FTaseMA displays considerable substrate plasticity. Although FTaseMA cannot accept D-allo-threonine, D-threonine or glycine or alanine or leucine as substrates, consistent with the previous studies of FTase from S. cattleya (Murphy et al. 2001), it can use L-Ser as substrate, albeit with low conversion of 4-FT as monitored in ${ }^{19} \mathrm{~F}-\mathrm{NMR}$. Most of the characterized LTTAs were found to accept L-Thr as the only retroaldol donor (Wu et al. 2020). Strikingly, the enzyme can also utilize L-allo-Thr as substrate with nine-fold less efficiency than the natural substrate L-Thr, a clear difference compared to other LTTAs. FTaseMA also accepts a range of electrophilic aldehyde acceptors with different functionalities, such as chloroacetaldehyde, glycolacetaldehyde, propanal, isobutyraldehyde, phenylacetaldehyde, when L-Thr was used, to generate different $\beta$ HAAs, suggesting that this enzyme could be used as a potential versatile biocatalyst to produce various $\beta$ HAAs (Wu et al. 2020). Of particular interests here is glycolacetaldehyde which is heavily hydrated in water. Seventy per cent of glycolacetaldehyde in the aqueous solutions exists as a diol form while only $4 \%$ is the aldehyde form (Collins and George 1971), further demonstrating the unusual ability of FTaseMA to dehydrate the diol of hydrated aldehyde species.

\section{LTTAs from the biosynthetic pathways of nucleoside antibiotic natural products}

Several lipopeptidyl nucleoside antibiotics, such as A-90289s 8 from Streptomyces sp. SANK 60405 (Fujita et al. 2011), and caprazamycins 9 from Streptomyces sp. MK730-62F (Igarashi et al. 2005), contain highly modified furanose motifs (Figs. 1 and 4). Previous isotopic labelling studies suggested that a C$\mathrm{C}$ bond forming event, possibly via an aldol mechanism, occurs extending the carbon chain at $\mathrm{C}-5^{\prime}$ of the canonical nucleoside to $\mathrm{C} 6$ or longer chain length of a so-called high-carbon nucleoside scaffold (Winn et al. 2010).

With the advance of genome sequencing technology in the last decade, the biosynthetic gene clusters (BGCs) of these nucleoside antibiotics have been identified for characterization (Barnard-Britson et al. 2012). Bioinformatics analysis of these clusters revealed that they shared an orf, putatively annotated as SHMT-like enzyme. This analysis was in line with the prediction of an aldol reaction that the putative SHMT ORFs may catalyse a biotransformation of Gly and nucleoside 5 -aldehyde 21 to yield the corresponding high-carbon nucleoside intermediates during the biosynthesis of these antibiotics.

Heterologous expression of lipK, encoding a putative SHMT in the BGC of A-90289s in S. lividan TK24, resulted in a soluble recombinant protein which contains a characteristic UV absorption maximum of $415 \mathrm{~nm}$, corresponding to a typical holo PLP-dependent enzyme (Fig. 2a). This UV absorption was abolished in a LipK variant where Lys 235 was changed to Ala, demonstrating that Lys235 is the key aa residue for the catalytic cycle (Barnard-Britson et al. 2012).

Tests on the activity of LipK with $\mathbf{2 1}$ and Gly or other Lamino acids revealed that only incubation of L-Thr resulted in the appearance of a new compound as observed in HPLC analysis. The identity of the new compound was confirmed to be the $\beta$ HAA containing glycine uracil 22 as evidenced by high-resolution MS and comprehensive 1D and 2D NMR analysis, in comparison to synthetic materials. The absolute stereochemistry of $\mathbf{2 2}$ was determined to be $\left(5^{\prime} S, 6^{\prime} S\right)$ through the diagnostic $J$ coupling value $\left(J_{\mathrm{H} 6^{\prime}-\mathrm{H} 5^{\prime}}=5.0 \mathrm{~Hz}\right)$ of the 


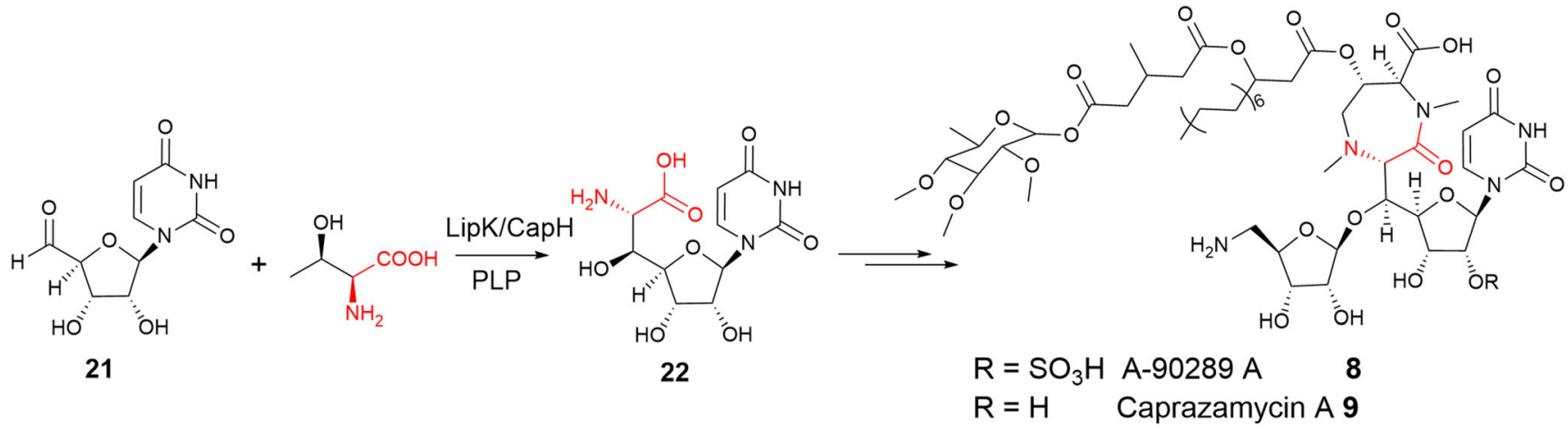

Fig. 4 LipK and CapH are two LTTAs catalysing the transaldolation between L-Thr and uracil 5'-aldehyde 21 in the biosynthetic pathways of lipopeptidyl nucleoside antibiotic natural products

derivatised synthetic and enzymatic 22. The enzyme displays restricted substrate specificity and only accepts L-Thr as the substrate. Unlike FTases, LipK is a single-domain LTTA. Further conserved genomic analysis indicated the occurrence of LipK homologues, suggesting that L-Thr transaldolation reaction may be more common than previously anticipated. LipK represents the second confirmed LTTA and the first subgroup of L-Thr:uridine-5'-aldehyde (UA) transaldolase to catalyse the biotransformation of $\beta$ HAA-containing nucleosides, providing a new biotechnological platform to prepare $\beta$ HAA-containing sugar previously difficult to be synthesized.

The second LipK-like LTTA, CapH, was identified in the BGC of capuramycin-type antibiotics A-500359s (Cai et al. 2015). Characterization of recombinant $\mathrm{CapH}$ revealed that $\mathrm{CapH}$ displays a similar biochemical property compared to LipK with restricted substrate specificity towards L-Thr. It has remained to be determined whether LipK or CapH utilises other nucleotide aldehydes except UA.

\section{LTTA from the pathway of $\beta$-lactone antibiotic}

The antibiotic natural product obafluorin 2 (Fig. 1) belongs to the chemical class of $\beta$-lactones, consisting of strained fourmembered rings, closely related to $\beta$-lactam family of antibiotics, such as penicillin. Obafluorin 2 contains an interesting $\beta$ HAA motif, $(R)$ - $\beta$-hydroxy- $p$-nitro-L-homophenylalanine ( $\beta$-OH- $p-\mathrm{NO}_{2}$-homoPhe) 23. In 2017, the corresponding BGC (oba/obi) of obafluorine 2 was identified in the producer, Pseudomonas fluorescens, by two research groups simultaneously (Schaffer et al. 2017; Scott et al. 2017). Bioinformatics analysis suggested that one of the orfs in the BGC encodes a putative bacterial SHMT albeit low aa identity $(25 \%)$. Overexpression of $o b i \mathrm{H}(o b a \mathrm{G})$ in E. coli resulted in the purification of the recombinant protein with unusual pink colour (Scott et al. 2017; Kumar et al. 2021). Biochemical assays coupled with isotopic labelling experiments demonstrated that $\mathrm{ObiH}(\mathrm{ObaG})$ is a new LTTA that catalyses the transaldolation between L-Thr and $p$-nitrophenylacetaldehyde $\mathbf{2 4}$ to generate a single stereoisomer of $\beta-\mathrm{OH}-p-\mathrm{NO}_{2}$-homoPhe with a yield of $55-59 \%$ (Scott et al. 2017).

$\mathrm{ObiH}(\mathrm{ObaG})$ displays a UV/Vis spectrum characteristic of PLP-dependent proteins, comprising absorption maxima at $340 \mathrm{~nm}$ and $390 \mathrm{~nm}$ that correspond to the internal ketoenamine $\mathbf{1 0}$ and enolimine 10a (Fig. 2a), respectively (Scott et al. 2017). The pink colour of ObiH attributing the UV absorption at $512 \mathrm{~nm}$ is correlated to the unusual internal quinonoid 10b (Fig. 2a), which is inactive state of the enzyme (Kumar et al. 2021). Exposing ObiH in the UV led to the rapid photoablation of the 515-nm peak and a temporary increase at $340 \mathrm{~nm}$, followed by decrease of $340 \mathrm{~nm}$ band and increase of $415 \mathrm{~nm}$ band, indicative of an isomerization between the enolimine 10a and ketoenamine $\mathbf{1 0}$ of the cofactor, respectively. Addition of L-Thr led to the formation of external glycyl quinonoid intermediate $\mathbf{1 3}$ that is remarkably persistent with a half-life of $\sim 3 \mathrm{~h}$, suggesting that $\mathrm{ObiH}$ catalyses the retro-aldol cleavage of L-Thr in the reaction cycle. The long lifetime of this glycyl quinonoid intermediate $\mathbf{1 3}$ would enable the enzyme reactivity with non-native aldehyde substrates for potential biocatalyst development.

ObiH displays considerably good substrate promiscuity towards aldehyde acceptors, phenylacetaldehydes, various aliphatic and extended aryl aldehydes as well as a range of aromatic aldehydes (Kreitler et al. 2019). For example, incubation of phenylacetaldehyde with $\mathrm{ObiH}$ led to a single stereoisomer, (2S)-amino-(3R)-hydroxy-4-phenylbutanoate 26a, while the reaction with benzaldehyde was less efficient leading to two products of L-threo and L-erythreo-phenylserine 26b in a ratio of 1:2 and poor overall yield (>20\%) (Fig. 5b) (Kreitler et al. 2019). Assay of an $\alpha$-branched isobutyraldehyde with $\mathrm{ObiH}$ resulted in the production of a single stereoisomer, $(2 S, 3 R)$ - $\beta$-hydroxy-Leu 26c, a $\beta$ HAA that is difficult to be chemically constructed involving multiple methods (Fig. 5b) (Kreitler et al. 2019). These results suggested that $\mathrm{ObiH}$ and its homologues hold a potential for 


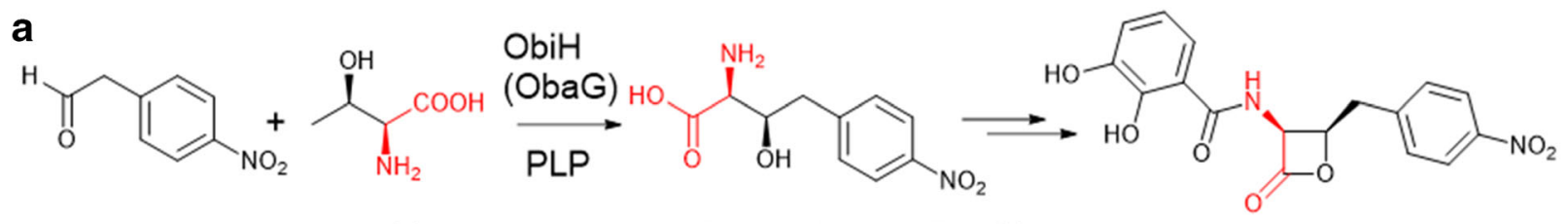

p-nitro-phenylacetaldehyde $\mathbf{2 4}$

$\beta-\mathrm{OH}-p-\mathrm{NO}_{2}$-homoPhe 23

Obafluorin 2

b<smiles>[R]C(=O)[CH-]C(O)C(N)C(=O)O</smiles>

aldehyde acceptors $\mathbf{2 5}$

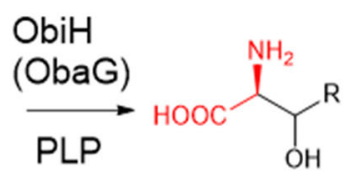

BHAAs 26

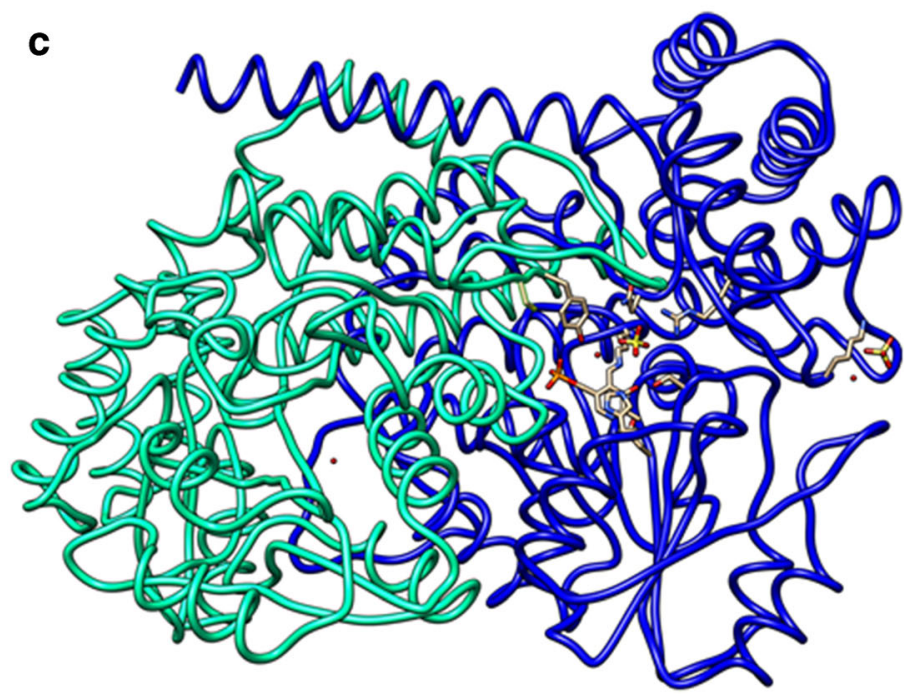

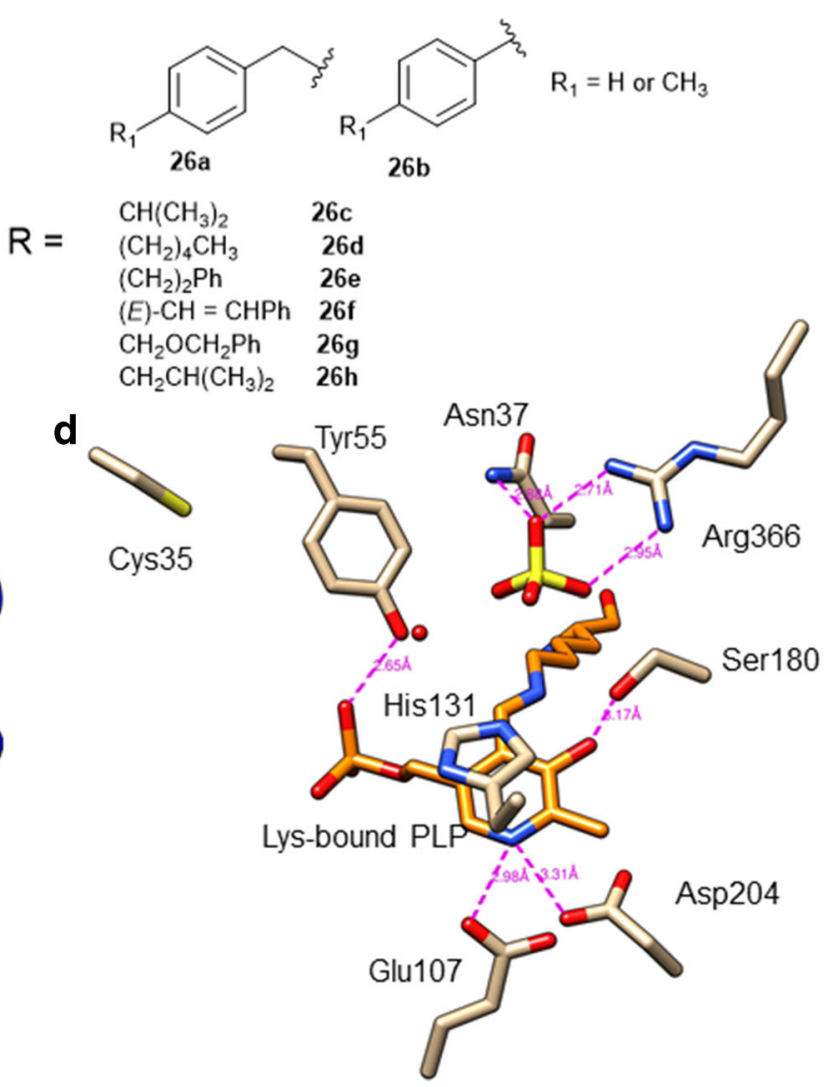

Fig. 5 a $\mathrm{ObiH}(\mathrm{ObaG})$ catalyses a transaldolation between L-Thr and $p$ nitro-phenylacetaldehyde $\mathbf{2 4}$ in the biosynthetic pathway of the $\beta$-lactone antibiotic natural product, obafluorine $\mathbf{2}$. b ObiH displays considerable substrate flexibility towards various aryl and aliphatic aldehydes. $\mathbf{c}$ The structure of $\mathrm{ObiH}$, the first structure of LTTA, indicating that $\mathrm{ObiH}$ forms a dimer (PDB access number: 7K34). Individual monomers are coloured in blue (chain A) and cyan (chain B). d The active site residues of $\mathrm{ObiH}$ are shown in sticks while the Lyn-bound PLP is shown in orange. Hydrogen bonds are shown as pink dashes. The active site of ObiH would allow targeted engineering approaches to further improve the efficiency of the transaldolation reactions catalysed by LTTAs in a broad context. high diastereoselectivity depending on the substrate aldehydes for the synthesis of enantiomerically pure L-threo- $\beta$ hydroxy- $\alpha$-amino acids.

The first crystal structure of LTTA was reported in 2021 (Kumar et al. 2021). ObiH (PDB number: 7K34) crystallized as a homodimer (Fig. 5c), with an extension of the C-terminus forming the dimer interface, consistent with other members of the fold-type I superfamily of PLP-dependent enzymes (Eliot and Kirsch 2004). The ObiH active site lies at the dimer interface, with most of the key residues contributed from a single unit (Kumar et al. 2021). Sequence alignment with other LTTAs and SHMTs and structural information revealed that Lys234, Arg366, His131, Tyr55 and Asp204 in the case of $\mathrm{ObiH}$ (Fig. 5d) are highly conserved and are in the close proximity of the PLP cofactor in the active site (Kumar et al. 2021). The pyridine ring of PLP is stacked with His 131, and the PLP phosphate is buried with extended H-bond networks, including two to Tyr55 and Asn268 from the partner subunit. Asp204 forms hydrogen bonds to the pyridine nitrogen of PLP, thereby increasing the electrophilicity of pyridinium moiety. Mutational analysis indicated that Asp204 is essential for the catalysis (Kumar et al. 2021).

\section{LTTA from the biosynthetic pathway of thioheptose nucleoside antibiotic natural products}

Albomycins 7 are sulphur-containing sideromycin antibiotics, which have intriguing structures consisting of a 6'-amino-4'- 
a<smiles>C[C@@H](O)C(N)C(=O)O</smiles>

5'-oxo-4'-thioxylofuranose nucleoside<smiles>N[C@@H](C(=O)O)[C@H](O)[C@H]1SC2C(O)C1[C@H]2n1ccc(=O)[nH]c1=O</smiles>

$28 a$<smiles>NC(C(=O)O)[C@@H](O)[C@]1(O)S[C@@H](n2ccc(=O)[nH]c2=O)C1O</smiles>

28b

27<smiles>C[C@@H](O)C(N)C(=O)O</smiles>

5'-oxo-4'-thio-D-ribofuranose nucleoside

29

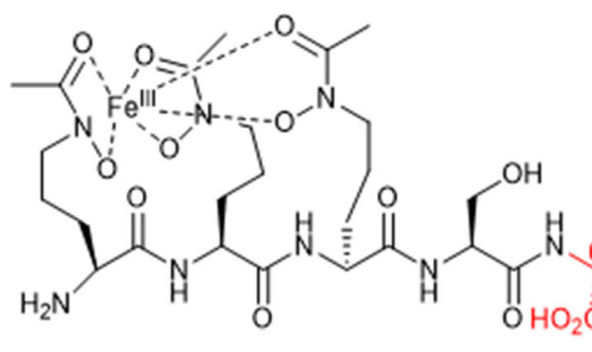

albomycin $\delta_{1} 7$

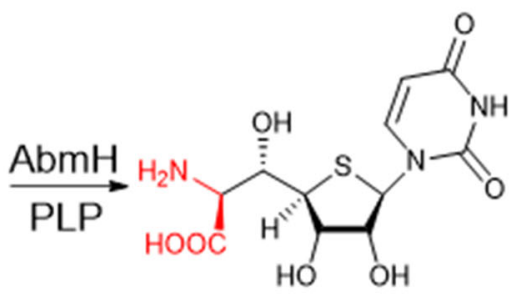

30

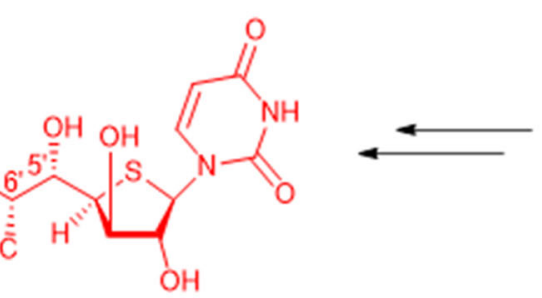

AbmD<smiles>NC(C(=O)O)[C@@H](O)[C@H]1SC(n2ccc(=O)[nH]c2=O)C(O)[C@H]1O</smiles>

28c

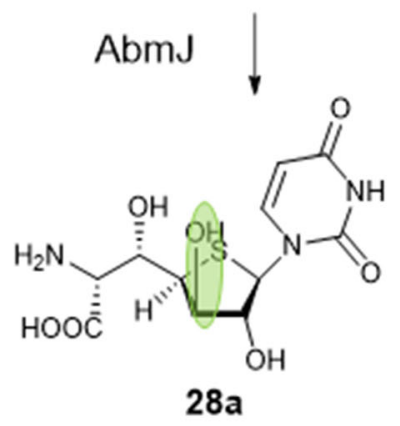

Fig. $6 \mathrm{AbmH}$ catalyses the transaldolation reaction between L-Thr and a very unusual thioribofuranose aldehyde substrate, followed by two epimerization events catalysed by a radical SAM AmbJ and PLP-dependent epimerase AmbD to finally install the thiopentose moiety in albomycins

thioheptose nucleoside $\mathbf{2 7}$ and an iron-chelating ferrichrome siderophore that are linked via amide linkage to an L-Ser residue (Fig. 6). Unlike lipopeptidyl nucleoside antibiotics such as A90289s that contain D-ribose and L-amino acid residues in the high-carbon nucleoside scaffold, albomycins has the Dconfiguration $\left(6^{\prime} R\right)$ of the $\alpha$-amino acid and the D-xylo-configuration $\left(3^{\prime} R\right)$ of the furanose ring in the thioheptose core which is rare occurrence found in nature. Bioinformatics analysis suggested that the corresponding BGC of albomycins contain an $\operatorname{orf}(a m b \mathrm{H})$, the gene product of which encodes an LTTA-like enzyme that was proposed to catalyse the transaldol reaction of L-Thr and 5'-oxo-4'-thioxylofuranose nucleoside 27 to form the $\mathrm{C}^{\prime} 5-\mathrm{C}^{\prime} 6$ bond in $\mathbf{2 8}$ (Fig. 6a).

However, biochemical analysis demonstrated that 5'-oxoD-thioribose nucleoside $\mathbf{2 9}$ is the bona fide substrate of recombinant AmbH (Ushimaru and Liu 2019). AmbH catalyses a regio- and stereo-selective transaldol reaction between L-Thr and 29 to yield the thioheptose core with a D-ribofuranose ring and an L-amino acid moiety 30, followed by the epimerization of the L-amino acid to generate D-amino acid catalysed by another PLP-dependent racemerase/epimerase AmbD to provide 28c. The D-thioribose ring to D-xylofuranose counterpart 28a is likely to be mediated by the radical SAM epimerase $\mathrm{AmbJ}$ based on the gene deletion and complementation experiments (Fig. 6b). The latter two epimerization events catalysed by AmbD and AmbJ appear to be essential for conferring the antimicrobial activity of albomycins despite no major structural alterations (Ushimaru and Liu 2019). AmbH displays considerable substrate plasticity toward $3^{\prime} R$-epimer of 29, D-xylose-based nucleoside aldehyde 27 (Fig. 6a), but the enzymatic products lost stereoselectivity, providing a mixture of stereoisomers (Ushimaru and Liu 2019). The insertion of a sulphur atom into the D-ribofuranose ring during the biosynthesis of albomycins has remained to be determined. 


\section{Discovery of LTTA homologue as biocatalysts}

The discovery of the single-domain LTTAs in the biosynthesis of natural products facilitates a conserved genomic approach with the aim of identifying new LTTA homologues. Given the importance of $\beta$ HAAs and difficulty of constructing enantiomer of $\beta$ HAAs, there has been a considerable attraction to utilising LTTA homologues as biocatalysts to provide a single-step synthesis of $\beta$ HAAs under the mild conditions with high stereoselectivity.

This is the case of PsLTTA from a Pseudomonas strain, which has $99 \%$ sequence identity to $\mathrm{ObiH}$ (Xu et al. 2019). Biochemical analysis demonstrated that PsLTTA accepts LThr as the donor substrate among Thr isomers but consumes a wide range of aromatic aldehydes with various substituents in $o, p, m$ position in the aromatic ring as acceptors (Fig. 7). Among these aldehyde acceptors, PsLTTA is able to mediate $p$-methylsulfonyl-benzaldehyde $\mathbf{3 1 b}$ and L-Thr to produce Lthreo-p-methylsulfonylphenylserine $\mathbf{3 2}$ with a high conversion rate and a high de value. It is worth noting that $\mathbf{3 2}$ is the key intermediate for synthesis of thiamphenicol and florfenicol. In an optimised condition, the whole cell containing overexpressed recombinant PsLTTA provided an excellent conversion of $67.1 \%$ with almost perfect stereoselective ratio of $94.5 \%$. Synthesis of $\mathbf{3 2}$ was also conducted in a 100 -mL scale of whole-cell biotransformation, first demonstrating that PSLTTA could be utilised as a robust biocatalyst for one-step preparation of $\beta$ HAAs.

\section{Directed evolution of mutated LTTA homologue with enhanced capacity}

One-step stereoselective enzymatic synthesis of $\beta$ HAAs has already attracted a considerable attention as this method offers better atomic economy under mild conditions with few byproducts generated compared to chemical synthesis. Although PsLTTA showed the potential to catalyse the asymmetric synthesis of $\mathbf{3 2}$, the overall productivity was moderate, preventing the enzyme to be used as viable biocatalysts.

There are two factors that influence the catalytic efficiency. Firstly, PsLTTA catalyses a reversible reaction depending on the concentrations of substrates and products. The accumulation of acetaldehyde may inhibit the forward transaldolation reaction. Secondly, the aldehyde donors are not the natural substrate of PsLTTA, resulting in low conversion and possibly less stereoselectivity. Therefore, it would be desirable to create an enzymatic system that consists of an engineered PsLTTA with an improved activity towards aldehyde acceptors and other enzymes to eliminate the accumulation of acetaldehyde.

Directed evolution has been proven to be a powerful method for improving biocatalyst's activities (Packer and Liu 2015). The key to apply directed evolution is to develop a high throughput screening (HTS) method (Ye et al. 2018). To this end, $\mathrm{Xu}$ et al. developed a coupled enzymatic reaction that can be used as the HTS (Xu et al. 2020). Firstly, they applied error-prone PCR method. Overexpression of PCR-mutated genes in $E$. coli and the whole-cell assays in 96-well plate with the reaction cocktail including PLP, aldehyde acceptor and L-Thr were carried out. In the reaction supernatants, alcohol dehydrogenase from Acetobacter pasteurianus (ApADH) was added to transform acetaldehyde to ethanol and convert NADH to $\mathrm{NAD}^{+}$, the latter activity of which can be assessed by monitoring the reduction of $\mathrm{NADH}$ at $340 \mathrm{~nm}$ (Fig. 8). More than 4000 colonies were screened. As a result, the double-point PsLTTA variant (PsLLTTAM2) where Asn35 and Cys57 were changed to Ser and Asn, respectively, was found to have the maximal enhanced production of the target BHAA with about 2.1-fold increase compared to wildtype PsLTTA in the whole-cell assays. Subsequently, PsLLTTAM2 was purified for biochemical characterization. The apparent catalytic efficiency $\left(k_{\mathrm{cat}} / K_{\mathrm{m}}\right)$ of PsLLTTAM2 was 7.2-fold higher than the one for

Fig. 7 A ObiH homologue, PsLTTA, catalyses a promiscuous transaldolation to generate various phenylserine derivatives<smiles>[R]c1cccc(C=O)c1</smiles>

31

$\mathrm{R}$

$\mathrm{H}$ p-MeSO $231 b$

$p-\mathrm{NO}_{2} \quad 31 \mathrm{c}$

$m-\mathrm{F}$ 310<smiles>C[C@@H](O)[C@H](N)C(=O)O</smiles>

$\underset{\text { PLP }}{\stackrel{\text { PsLTTA }}{\longrightarrow}}$

de $(\%)$

77.2

79.9

76.7

66.4

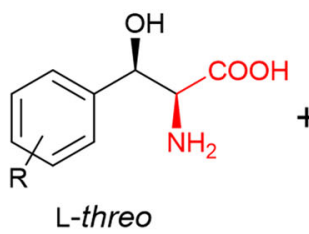
32

$\mathrm{R}$ $m-\mathrm{NO}_{2}$ o-F o-Cl $\mathrm{o}-\mathrm{Br}$ $\mathrm{o}-\mathrm{NO}_{2}$<smiles>[R]c1ccc([C@@H](O)[C@@H](N)C(=O)O)cc1</smiles>
L-erythro 33

\begin{tabular}{|c|c|c|c|}
\hline & & Conversion (\%) & de $(\%)$ \\
\hline$-\mathrm{NO}_{2}$ & $31 \mathrm{e}$ & 25.2 & 29.9 \\
\hline & $31 f$ & 43.5 & 69.2 \\
\hline $\mathrm{Cl}$ & $31 \mathrm{~g}$ & 37.5 & 80.3 \\
\hline$B$ & $31 \mathrm{~h}$ & 43.3 & 80.8 \\
\hline $\mathrm{D}_{2}$ & 31 & 40.5 & 50.2 \\
\hline
\end{tabular}




\section{Protein engineering of searching biocatalysts with enhanced capacity}

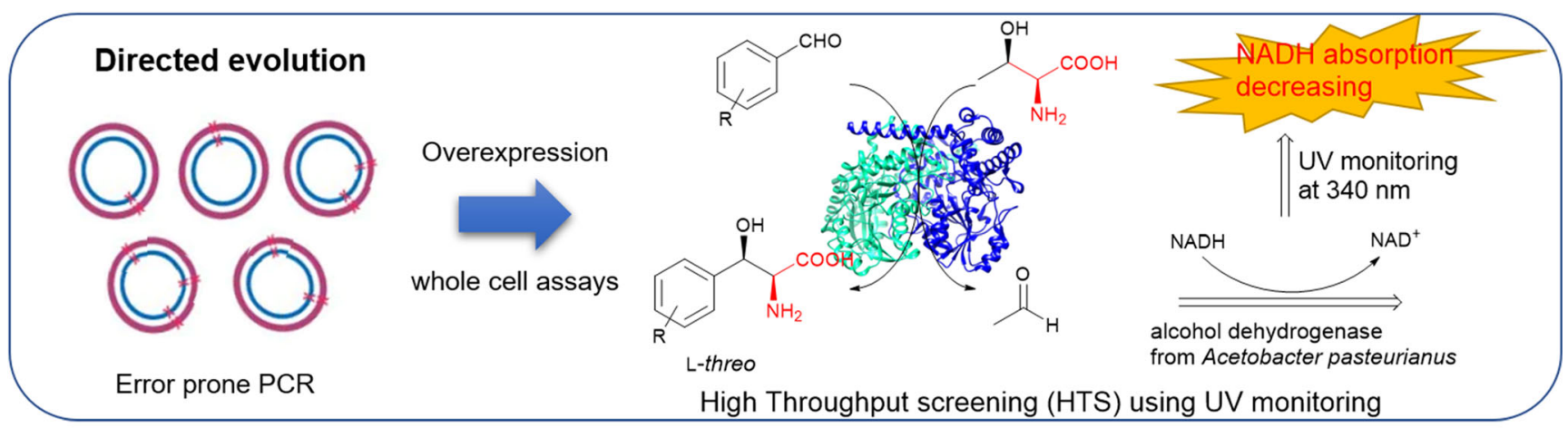

\section{Synthetic biology enabling improved production of HAAs}

- Suitable buffer

- A low wet cells concentration

- A low temperature

- Proper co-solvent

- Substrates concentration

- Acetaldehyde elimination

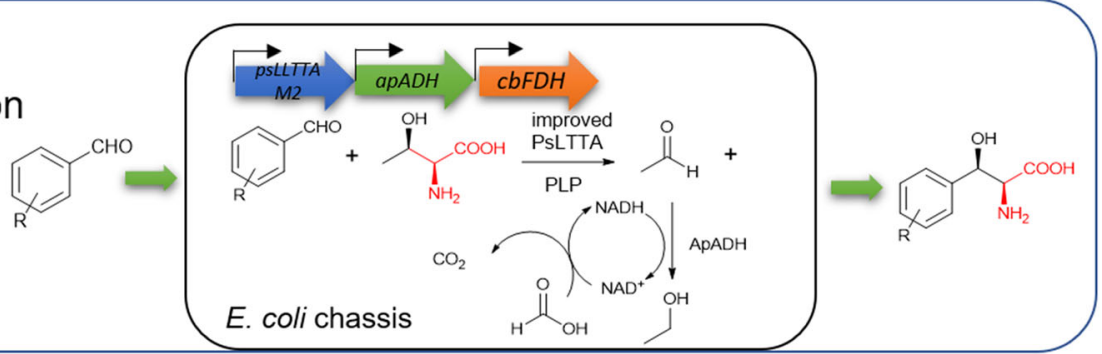

Fig. 8 Directed evolution and high throughput screening development enable the discovery of a PsLTTA variant with higher enantioselectivity and productivity, followed by synthetic biology approach to create an engineered $E$. coli chassis for $\beta$ HAA production.

wild-type PsLLTTA. It is worth noting that such two mutations in PsLLTTA are consistent with the assessment of the structure of ObiH (Kumar et al. 2021) that Asn35 is in the active site of the enzyme and that Cys57 is within a highly mobile loop.

To further improve the yield of $\beta$ HAA produced by PsLLTTAM2, Xu et al (Xu et al. 2020) developed a regeneration cycle of NADH coupling with the third enzyme, formate dehydrogenase from Candida boidinii (CbFDH), to convert $\mathrm{NAD}^{+}$back to NADH using formic acid as substrate (Fig. 8). Such an acetaldehyde elimination system significantly improved the titre of $\mathbf{3 2}$ by 4 -fold $(61.3 \mathrm{mM})$ compared to the one without the acetaldehyde elimination system in the wholecell studies (Xu et al. 2020). Finally, an engineered E. coli chassis was generated, which contains three genes, psLLTTAM2, cbFDH and apADH. The titre of $\mathbf{3 2}$ from this engineered strain was further up to $101.7 \mathrm{mM}, 8.8$-fold increase compared to the single system of PsLLTTA. The benefit for this synthetic biology approach is that the biotransformation generates ethanol as the by-product. However, the high concentration of accumulated ethanol may inhibit the growth of this engineered $E$. coli, resulting in low productivity of $\beta$ HAAs in turn in the industrial setting. Therefore, it may be worthy considering using other microbial chassis with high tolerance of ethanol production in the future development.

\section{Conclusion and future perspectives}

Although the first LTTA was discovered almost two decades ago, the catalytic potential of this group of enzymes was only assessed during the last decade, coincident with the advanced genome sequencing technology. Much is still needed to expand the scope of LTTA biocatalysts for asymmetric synthesis of industrially important $\beta$ HAAs. It is exciting to fully use the existing enzyme inventory to accommodate new chemistries for biotechnologically viable $\beta$ HAA synthesis. Within this limited pool of identified enzymes, some LTTAs display great substrate flexibility toward aldehyde acceptors with considerably good stereoselectivity. However, the overall productivity of the BHAAs is not yet desirable as a viable biocatalyst. As a complement to this, we should also turn our attention to protein engineering to enhance the activities of the promising enzyme candidates. This was exemplified by the recent HTS method which has set a framework for directed evolution of LTTAs (Fig. 8).

Another potential exciting development is to turn our attention to nature for inspirations by discovering new $3 \mathrm{HAA}$ containing entities through natural product programmes and new LTTAs with broad substrate specificity, better kinetics, high regio- and stereo-selectivity and good tolerance towards reaction conditions (i.e. organic solvents, temperatures) by genomic mining strategy (Fig. 8). It should be noted that the 
Fig. 9 a Protein motif analysis suggested that LTTAs contain two unique aa motifs compared to E. coli SHMT enzyme. Some of aa residues are highly conserved among LTTAs. b The hydrogen bond network formed among $\mathrm{H} 324$ and Q325 with the residues, H207 and R366, in the active site of ObiH is shown as pink dashes. Lys-bound PLP is shown in orange

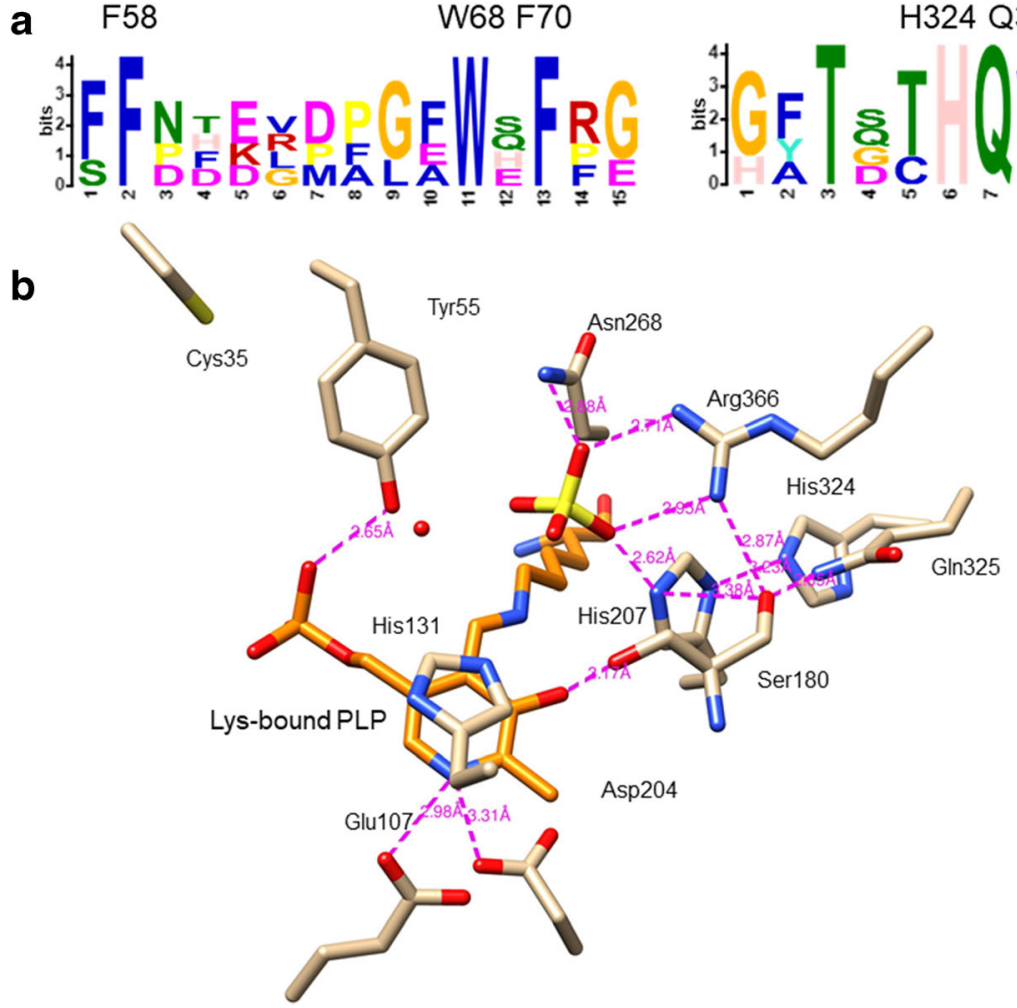

majority of LTTAs was identified from two bacterial species, actinomycetes and pseudomonas, in the current enzyme inventory. Protein motif analysis (Bailey et al. 2009) combined with the available structure data of ObiH (Kumar et al. 2021) suggested that LTTAs contain unique conserved motifs, including F58, W68 and F70 in the mobile loop of ObiH, and H324 and Q325 which form extensive hydrogen bond network with the residues, H207 and R366, in the active site of ObiH (Fig. 9). This information could serve as guidance for future LTTA mining. Therefore, efforts directed towards LTTA candidates from other microbial genus will certainly offer a promising opportunity of discovering a biotechnologically viable biocatalyst for $\beta$ HAA synthesis.

Author contribution S.W. and H.D. wrote the review and have contributed equally to this work. S.W. and H.D. edited this review. S.W. and H.D. designed the structure and revised this review.

Funding This study was funded by Biotechnology and Biological Sciences Research Council UK (BBSRC) (BB/P00380X/1, BB/ R00479X/1 and BB/R50547X/1), Scottish Funding Council COVID-19 Grant extension and Bridging Fund, and Industrial Biotechnology Innovation Centre (IBioIC, Scotland).

\section{Declarations}

Ethical statement This article does not contain any studies with animals performed by any of the authors.
Conflict of interest The authors declare no competing interests.

Open Access This article is licensed under a Creative Commons Attribution 4.0 International License, which permits use, sharing, adaptation, distribution and reproduction in any medium or format, as long as you give appropriate credit to the original author(s) and the source, provide a link to the Creative Commons licence, and indicate if changes were made. The images or other third party material in this article are included in the article's Creative Commons licence, unless indicated otherwise in a credit line to the material. If material is not included in the article's Creative Commons licence and your intended use is not permitted by statutory regulation or exceeds the permitted use, you will need to obtain permission directly from the copyright holder. To view a copy of this licence, visit http://creativecommons.org/licenses/by/4.0/.

\section{References}

Ashford PA, Bew SP (2012) Recent advances in the synthesis of new glycopeptide antibiotics. Chem Soc Rev 41:957-978. https://doi. org $/ 10.1039 / \mathrm{c} 1 \mathrm{cs} 15125 \mathrm{~h}$

Bailey TL, Boden M, Buske FA, Frith M, Grant CE, Clementi L, Ren J, Li WW, Noble WS (2009) MEME Suite: tools for motif discovery and searching. Nucleic Acids Res 37:W202-W208. https://doi.org/ 10.1093/nar/gkp335

Barnard-Britson S, Chi X, Nonaka K, Spork AP, Tibrewal N, Goswami A, Pahari P, Ducho C, Rohr J, Van Lanen SG (2012) Amalgamation of nucleosides and amino acids in antibiotic biosynthesis: discovery of an L-threonine: uridine-5'-aldehyde transaldolase. J Am Chem Soc 134:18514-18517. https://doi.org/10.1021/ja308185q 
Cai W, Goswami A, Yang Z, Liu X, Green KD, Barnard-Britson S, Baba S, Funabashi M, Nonaka K, Sunkara M, Morris AJ, Spork AP, Ducho C, Garneau-Tsodikova S, Thorson JS, Van Lanen SG (2015) The biosynthesis of capuramycin-type antibiotics: identification of the A-102395 biosynthetic gene cluster, mechanism of selfresistance, and formation of uridine-5'-carboxamide. J Biol Chem 290:13710-13724. https://doi.org/10.1074/jbc.M115.646414

Cobb SL, Deng H, Hamilton JTG, McGlinchey RP, O’Hagan D (2004) Identification of 5-fluoro-5-deoxy-D-ribose-1-phosphate as an intermediate in fluorometabolite biosynthesis in Streptomyces cattleya. Chem Commun:592-593. https://doi.org/10.1039/B400754A

Collins GCS, George WO (1971) Nuclear magnetic resonance spectra of glycolaldehyde. J Chem Soc B Phys Org:1352-1355. https://doi. org/10.1039/J29710001352

Deng H, Cross SM, McGlinchey RP, Hamilton JTG, O’Hagan D (2008) In vitro reconstituted biotransformation of 4-fluorothreonine from fluoride ion: application of the fluorinase. Chem Biol 15:1268 1276. https://doi.org/10.1016/j.chembiol.2008.10.012

Deng H, Ma L, Bandaranayaka N, Qin Z, Mann G, Kyeremeh K, Yu Y, Shepherd T, Naismith JH, O'Hagan D (2014) Identification of fluorinases from Streptomyces sp MA37, Norcardia brasiliensis, and Actinoplanes sp N902-109 by genome mining. ChemBioChem 15:364-368. https://doi.org/10.1002/cbic. 201300732

Deng H, O'Hagan D, Schaffrath C (2004) Fluorometabolite biosynthesis and the fluorinase from Streptomyces cattleya. Nat Prod Rep 21: 773-784. https://doi.org/10.1039/B415087M

Dong C, Huang F, Deng H, Schaffrath C (2004) Crystal structure and mechanism of a bacterial fluorinating enzyme. Nature. 427:561565. https://doi.org/10.1038/nature02303.1

Du Y, Ryan KS (2019) Pyridoxal phosphate-dependent reactions in the biosynthesis of natural products. Nat Prod Rep 36:430-457. https:// doi.org/10.1039/c8np00049b

Eliot AC, Kirsch JF (2004) Pyridoxal phosphate enzymes: mechanistic, structural, and evolutionary considerations. Annu Rev Biochem 73: 383-415. https://doi.org/10.1146/annurev.biochem.73.011303. 074021

Fesko K (2016) Threonine aldolases: perspectives in engineering and screening the enzymes with enhanced substrate and stereo specificities. Appl Microbiol Biotechnol 100:2579-2590. https://doi.org/10. 1007/s00253-015-7218-5

Fujita Y, Kizuka M, Funabashi M, Ogawa Y, Ishikawa T, Nonaka K, Takatsu T (2011) A-90289 A and B, new inhibitors of bacterial translocase I, produced by Streptomyces sp. SANK 60405. J Antibiot (Tokyo) 64:495-501. https://doi.org/10.1038/ja.2011.38

Hamilton JTG, Amin MR, Harper B, Hagan DO, Spx BT (1997) Biosynthesis of fluoroacetate and 4-fluorothreonine by Streptomyces cattleya. Glycine and pyruvate as precursors. Chem Commun:797-798. https://doi.org/10.1039/A700495H

Hamilton JTG, Murphy CD, Amin MR, Hagan DO, Harper DB (1998) Exploring the biosynthetic origin of fluoroacetate and 4fluorothreonine in Streptomyces cattleya. Chem Commun:759767. https://doi.org/10.1039/A706554J

Hauser RA, Heritier S, Rowse GJ, Hewitt LA, Isaacson SH (2016) Droxidopa and reduced falls in a trial of Parkinson disease patients with neurogenic orthostatic hypotension. Clin Neuropharmacol 39: 220-226. https://doi.org/10.1097/WNF.0000000000000168

Hibi M, Kasahara T, Kawashima T, Yajima H, Kozono S, Smirnov SV, Kodera T, Sugiyama M, Shimizu S, Yokozeki K, Ogawa J (2015) Multi-enzymatic synthesis of optically pure $\beta$-hydroxy $\alpha$-amino acids. Adv Synth Catal 357:767-774. https://doi.org/10.1002/adsc. 201400672

Huang F, Haydock SF, Spiteller D, Mironenko T, Li T, Hagan DO, Leadlay PF, Spencer JB (2006) The gene cluster for fluorometabolite biosynthesis in Streptomyces cattleya: a thioesterase confers resistance to fluoroacetyl-coenzyme A. Chem Biol 13:475-484. https://doi.org/10.1016/j.chembiol.2006.02.014

Huang S, Ma L, Tong MH, Yu Y, O’Hagan D, Deng H (2014) Fluoroacetate biosynthesis from the marine-derived bacterium Streptomyces xinghaiensis NRRL B-24674. Org Biomol Chem: 4828-4831. https://doi.org/10.1039/c4ob00970c

Hüttel W (2021) Echinocandins: structural diversity, biosynthesis, and development of antimycotics. Appl Microbiol Biotechnol 105:5566. https://doi.org/10.1007/s00253-020-11022-y

Igarashi M, Takahashi Y, Shitara T, Nakamura H, Naganawa H, Miyake T, Akamatsu Y (2005) Caprazamycins, novel Lipo-nucleoside antibiotics, from Streptomyces sp. J Antibiot (Tokyo) 58:327-337. https://doi.org/10.1038/ja.2005.41

Kreitler DF, Gemmell EM, Schaffer JE, Wencewicz TA, Gulick AM (2019) The structural basis of $\mathrm{N}$-acyl- $\alpha$-amino- $\beta$-lactone formation catalyzed by a nonribosomal peptide synthetase. Nat Commun 10: 1-13. https://doi.org/10.1038/s41467-019-11383-7

Kumar P, Meza A, Ellis JM, Carlson GA, Bingman CA, Buller AR (2021) L-threonine transaldolase activity is enabled by a persistent catalytic intermediate. ACS Chem Biol 16:86-95. https://doi.org/10. 1021/acschembio.0c00753

Levitskiy OA, Grishin YK, Magdesieva TV (2019) Stereoselective electrosynthesis of -hydroxy- $\alpha$-amino acids in the form of Ni II Schiff-base complexes. Eur J Org Chem 3174-3182:3174-3182. https://doi.org/10.1002/ejoc.201900466

Lu W, Chen P, Lin G (2008) New stereoselective synthesis of thiamphenicol and florfenicol from enantiomerically pure cyanohydrin: a chemo-enzymatic approach. Tetrahedron 64:7822-7827. https://doi.org/10.1016/j.tet.2008.05.113

Ma L, Bartholome A, Tong MH, Qin Z, Yu Y, Shepherd T, Kyeremeh K, Deng H, O'Hagan D (2015) Identification of a fluorometabolite from Streptomyces sp. MA37: (2R3S4S)-5-fluoro-2,3,4trihydroxypentanoic acid. Chem Sci:1414-1419. https://doi.org/10. $1039 / \mathrm{c} 4 \mathrm{sc} 03540 \mathrm{~b}$

Maruyama W, Naoi M, Narabayashi H (1996) The metabolism of LDOPA and L-threo-3,4-dihydroxyphenylserine and their effects on monoamines in the human brain: analysis of the intraventricular fluid from parkinsonian patients. J Neurol Sci 139:141-148. https://doi.org/10.1016/0022-510X(96)00049-4

Masruri, Willis AC, McLeod MD (2012) Osmium-catalyzed vicinal oxyamination of alkenes by $\mathrm{N}$-(4- toluenesulfonyloxy) carbamates. J Organomet Chem 77:8480-8491. https://doi.org/10.1021/ jo301372y

Moreira IS, Amorim CL, Murphy CD, Castro PML (2018) Strategies for biodegreadation of fluorinated compounds. In: Prasad, Aranda (eds) Approaches in Bioremediation. Springer, Cham, pp 239-280

Moss SJ, Murphy CD, Hamilton JTG, Mcroberts WC, Hagan DO, Schaffrath C, Harper DB (2000) Fluoroacetaldehyde: a precursor of both fluoroacetate and 4-fluorothreonine in Streptomyces cattleya. Chem Commun:2281-2282. https://doi.org/10.1039/ b007261n

Murphy CD, O'Hagan D, Schaffrath C (2001) Identification of a PLPdependent threonine transaldolase: a novel enzyme involved in 4fluorothreonine biosynthesis in Streptomyces cattleya. Angew Chem Int Ed 40:4479-4481

Nieschalk J, Hamilton JTG, Murphy CD, Harper B, Hagan DO (1997) Biosynthesis of fluoroacetate and 4-fluorothreonine by Streptomyces cattleya. The stereochemical processing of glycerol. Chem Commun:799-800. https://doi.org/10.1039/A700498B

O’Hagan D, Deng H (2015) Enzymatic fluorination and biotechnological developments of the fluorinase. Chem Rev 115:634-649. https:// doi.org/10.1021/cr500209t

O'Hagan D, Schaffrath C, Cobb SL, Hamilton JTG (2002) Biosynthesis of an organofluorine molecule. Nature. 416:279. https://doi.org/10. $1038 / 416279$ a 
Packer MS, Liu DR (2015) Methods for the directed evolution of proteins. Nat Rev Genet 16:379-394. https://doi.org/10.1038/nrg3927

Richard JP, Amyes TL, Crugeiras J, Rios A (2009) Pyridoxal 5'-phosphate: electrophilic catalyst extraordinaire. Curr Opin Chem Biol 13(4):475-483. https://doi.org/10.1016/j.cbpa.2009.06.023

Samland AK, Rale M, Sprenger GA, Fessner W (2011) The transaldolase family: new synthetic opportunities from an ancient enzyme scaffold. ChemBioChem. 12:1454-1474. https://doi.org/10.1002/cbic. 201100072

Sanada M, Miyano T, Iwadare S, Williamson JM, Arison BH, Smith JL, Douglas AW, Liesch JM, Inamine E (1986) Biosynthesis of fluorothreonine and fluoroacetic acid by the thienamycin producer, Streptomyces cattleya. J Antibiot (Tokyo) 39:259-265. https://doi. org/10.7164/antibiotics.39.259

Schaffer JE, Reck MR, Prasad NK, Wencewicz TA (2017) $\beta$-lactone formation during product release from a nonribosomal peptide synthetase. Nat Chem Biol 13:737-744. https://doi.org/10.1038/ nchembio. 2374

Scott TA, Heine D, Qin Z, Wilkinson B (2017) An L-threonine transaldolase is required for L-threo- $\beta$-hydroxy- $\alpha$-amino acid assembly during obafluorin biosynthesis. Nat Commun 8:1-11. https://doi.org/10.1038/ncomms15935

Seiple IB, Mercer JAM, Sussman RJ, Zhang Z, Myers AG (2014) Stereocontrolled synthesis of syn- $\beta$-hydroxy- $\alpha$-amino acids by direct aldolization of pseudoephenamine glycinamide. Angew Chem Int Ed 53:4642-4647. https://doi.org/10.1002/anie.201400928

Singjunla Y, Baudoux J, Rouden J (2013) Direct synthesis of $\beta$-hydroxy$\alpha$-amino acids via diastereoselective decarboxylative aldol reaction. Org Lett 15(22):5770-5773. https://doi.org/10.1021/o1402805f

Sugiyama H, Shioiri T, Yokokawa F (2002) Syntheses of four unusual amino acids, constituents of cyclomarin A. Tetrahedron Lett 43: 3489-3492. https://doi.org/10.1016/S0040-4039(02)00607-X

Tailhades J, Zhao Y, Ho YTC, Greule A, Ahmed I, Schoppet M, Kulkarni K, Goode RJA, Schittenhelm RB, Voss JJ, De CMJ (2020) A chemoenzymatic approach to the synthesis of glycopeptide antibiotic analogues. Angew Chem Int Ed:10991-10995. https://doi.org/ 10.1002/ange. 202003726

Ushimaru R, Liu HW (2019) Biosynthetic origin of the atypical stereochemistry in the thioheptose core of albomycin nucleoside antibiotics. J Am Chem Soc 141:8-11. https://doi.org/10.1021/jacs. $8 \mathrm{~b} 12565$

Wang Y, Deng Z, Qu X (2014) Characterization of a SAM-dependent fluorinase from a latent biosynthetic pathway for fluoroacetate and 4-fluorothreonine formation in Nocardia brasiliensis. F1000Research 3:61. https://doi.org/10.12688/f1000research.3-61. $\mathrm{v} 1$

Winn M, Goss RJM, Kimura KI, Bugg TDH (2010) Antimicrobial nucleoside antibiotics targeting cell wall assembly: recent advances in structure-function studies and nucleoside biosynthesis. Nat Prod Rep 27:279-304. https://doi.org/10.1039/b816215h

Wu L, Maglangit F, Deng H (2020) Fluorine biocatalysis. Curr Opin Chem Biol 55:119-126. https://doi.org/10.1016/j.cbpa.2020.01.004

Wu L, Tong MH, Kyeremeh K (2020) Identification of 5-fluoro-5-deoxyribulose as a shunt fluorometabolite in Streptomyces sp. MA37. Biomolecules. 1-11. https://doi.org/10.3390/biom10071023

Wu L, Tong MH, Raab A, Fang Q, Wang S, Kyeremeh K, Yu Y, Deng H (2020) An unusual metal-bound 4-fluorothreonine transaldolase from Streptomyces sp. MA37 catalyses promiscuous transaldol reactions. Appl Microbiol Biotechnol. https://doi.org/10.1007/ s00253-020-10497-z

Xu L, Wang LC, Su BM, Xu XQ, Lin J (2020) Multi-enzyme cascade for improving $\beta$-hydroxy- $\alpha$-amino acids production by engineering $L$ threonine transaldolase and combining acetaldehyde elimination system. Bioresour Technol 310:123439. https://doi.org/10.1016/j. biortech.2020.123439

Xu L, Wang LC, Xu XQ, Lin J (2019) Characteristics of L-threonine transaldolase for asymmetric synthesis of $\beta$-hydroxy- $\alpha$-amino acids. Catal Sci Technol 9:5943-5952. https://doi.org/10.1039/ c9cy01608b

Ye L, Yang C, Yu H (2018) From molecular engineering to process engineering: development of high-throughput screening methods in enzyme directed evolution. Appl Microbiol Biotechnol 102: 559-567. https://doi.org/10.1007/s00253-017-8568-y

Yim G, Thaker MN, Koteva K, Wright G (2014) Glycopeptide antibiotic biosynthesis. J Antibiot (Tokyo) 67:31-41. https://doi.org/10.1038/ ja.2013.117

Zhao C, Li P, Deng Z, Ou H, Mcglinchey RP, Hagan DO (2012) Insights into fluorometabolite biosynthesis in Streptomyces cattleya DSM46488 through genome sequence and knockout mutants. Bioorg Chem 44:1-7. https://doi.org/10.1016/j.bioorg.2012.06.002

Publisher's note Springer Nature remains neutral with regard to jurisdictional claims in published maps and institutional affiliations. 